\title{
Antioxidant Activity of Goldenrod (Solidago virgaurea) Leaf and Stem Powder on Raw Ground Pork during Chilled Storage
}

\author{
Yong-Jae Kim, Hack-Youn Kim ${ }^{1}$, Ju-Hui Choe, Jae-Hyun Park, Youn-Kyung Ham, \\ Eui-Joo Yeo, Ko-Eun Hwang, and Cheon-Jei Kim* \\ Department of Food Science and Biotechnology of Animal Resources, Konkuk University, Seoul 143-701, Korea \\ ${ }^{I}$ Department of Animal Resources Science, Kongju National University, Yesan 340-702, Korea
}

\begin{abstract}
The effects of adding goldenrod leaf powder (GLP) and goldenrod stem powder (GSP) $(0.1 \%$ and $0.5 \%)$ to raw ground pork on antioxidant activity were examined. The following six treatment groups were used: Control (without antioxidant), GLP1 (with 0.1\% GLP), GLP2 (with 0.5\% GLP), GSP1 (with 0.1\% GSP), GSP2 (with 0.5\% GSP) and AS (with 0.05\% ascorbic acid). The chemical compositions, $\mathrm{pH}$ values, instrumental color, conjugated diene (CD), free fatty acids (FFA) and thiobarbituric acid-reactive substance (TBARS) value were measured during $15 \mathrm{~d}$ of storage at chilled temperatures. The addition of GLP and GSP showed no effect on moisture, protein and fat contents of the samples. However, adding $0.5 \%$ GSP increased the ash contents of ground pork $(p<0.05)$. The $\mathrm{pH}$ values of treated samples decreased until day 7 , and then increased thereafter. The addition of GLP and GSP decreased the $L^{*}$ and $a^{*}$ values and increased the $b^{*}$ value $(p<0.05)$. The CD, FFA and TBARS value of the control were higher $(p<0.05)$ than samples containing GLP and GSP. The addition of GLP and GSP resulted in a significant decrease in CD, FFA and TBARS values. Overall, this study demonstrated that GL and GS could be used as an antioxidant of raw ground pork.
\end{abstract}

Key words: goldenrod leaf powder, goldenrod stem powder, antioxidant activity, raw ground pork, chilled storage

\section{Introduction}

Lipid is a major nutrient in meat and has been reported to enhance the properties of meat product, including the flavor, tenderness, and juiciness (Linda, 2005). However, an excess of lipids can cause rapid lipid oxidation. Lipid oxidation is mostly initiated in the polyunsaturated fatty acids, leading to the production of free radical. Free radicals promote additional oxidation or decomposition to secondary reaction products such as aldehydes, ketones and other oxygenated compounds that produce adverse effects. As a result, lipid oxidation progress can significantly deteriorate the quality of meat products, such as an development of the rancid flavor, discoloration, loss of nutritional value, and limiting shelf-life (Frankel, 1950).

Several synthetic antioxidants have been used in the meat product industry to prevent lipid oxidation, including butylated hydroxyltoluene (BHT), and butylated

\footnotetext{
*Corresponding author: Cheon-Jei Kim, Department of Food Science and Biotechnology of Animal Resources, Konkuk University, Seoul 143-701, Korea. Tel: 82-2-450-3684, Fax: 82-2444-6695, E-mail: kimcj@konkuk.ac.kr
}

hydroxyanisole (BHA). These antioxidants were generally used because of their strong antioxidant activity and economic efficiency. However, several researches have reported that use of synthetic antioxidants may cause health risk (Chen et al., 1992; Sherwin, 1990; Sun and Fukuhara, 1997). BHA was classified as group 2B by the International Agency for Research on Cancer and has been Regarded as a human carcinogen by National Institutes of Health. In addition, BHT has been shown to cause internal and external haemorrhaging in some experimental animals (Shahi and Wanasundara, 1992). For these reasons, there has been an increasing demand to decrease the use of synthetic antioxidants (Namiki, 1990) and an increase in the demand for natural antioxidants that dsiplay no toxicity and health risks. Recently, several natural antioxidants have been studied from plant. Plants contain lots of polyphenolic compounds, which have been extensively known to have antioxidant activity. McCarthy et al., (2001) studied the antioxidant activity from aloe vera, fenugreek, ginseng, mustard, rosemary, sage, tea catechins. In addition, Bandyopadhyay et al. (2008) studied natural antioxidant from viz. beet (Beta vulgaris), mint (Mentha spicata L.) and ginger (Zingiber 
officinale L.).

Goldenrod (Solidago virgaurea) is an herbaceous perennial plant that involves the family Asteraceae. Goldenrod contains abundant vitamins, such as vitamin A, $\beta$ carotene and various mineral as phosphorus, calcium and iron. Choi et al. (2010) reported that goldenrod has DPPH radical scavenging activity and antimicrobial activities. Starks et al. (2011) observed that goldenrod extract was a biosynthetic material that presented an antimicrobial effect called clerodane. Furthermore, Kim et al. (2011a) found that the goldenrod extract produced an anti-inflammatory effect.

Therefore, the objective of this study was to examine the effects of Goldenrod (Solidago virgaurea) leaf and stem powder on the oxidative stability of raw ground pork during over $15 \mathrm{~d}$ of storage at chilled temperatures.

\section{Materials and Methods}

\section{Preparation of goldenrod (Solidago virgaurea) leaf and stem powder}

The goldenrod were washed and cut to separate the leaves and stems. The leaves and stems were cut into small pieces, dried in a hot air dryer (Enex-Co-600, Enex, Korea) at $50^{\circ} \mathrm{C}$ for $15 \mathrm{~h}$, and powdered (35 mesh). Goldenrod powders were stored at $-18^{\circ} \mathrm{C}$ prior to the experiment.

\section{Preparation of meat samples}

Fresh pork hams and back fats were purchased from a pilot plant at Konkuk University, Korea, $48 \mathrm{~h}$ postmortem. All subcutaneous and intramuscular fat and visible connective tissues were removed from the fresh ham muscles.

The ground meat samples were produced using the following formulation: $73.5 \%$ lean pork meat, $20 \%$ pork back fat, $5 \%$ Ice, and $1.5 \%$ salt. The lean pork meat and pork back fat were ground through a $3 \mathrm{~mm}$ grinding plate and then ice and salt were added. The goldenrod leaf and stem powder were added according to the following formulation: Con (without antioxidant); GLP1 (with $0.1 \%$ goldenrod leaf powder); GLP2 (with $0.5 \%$ goldenrod leaf powder); GSP1 (with $0.1 \%$ goldenrod stem powder); and GSP2 (with $0.5 \%$ goldenrod stem powder); AS (with $0.05 \%$ ascorbic acid). These percentages were based on the formula weight of the ground meat samples without the antioxidant extract. Samples were hand mixed for $5 \mathrm{~min}$. The mixed meat was then anaerobically packaged in $\mathrm{PE} /$ nylon film bags, spread to a thickness of $2.5 \mathrm{~cm}$ and, stored at
$4 \pm 1^{\circ} \mathrm{C}$ for $15 \mathrm{~d}$.

\section{Chemical compositions}

The chemical compositions of the samples were determined using standard AOAC (2000) methods. The moisture content was determined based on the weight loss after $12 \mathrm{~h}$ of drying at $105^{\circ} \mathrm{C}$ in a drying oven (SW-90D, Sang Woo Scienctific Co., Korea). The fat content was determined using the Sohxlet method with a solvent extraction system (Soxtec ${ }^{\circledR}$ Avanti 2050 Auto System, Foss Tecator AB, Sweden). The protein content was determined using the Kjeldahl method with an automatic Kjeldahl nitrogen analyzer (Kjeltec ${ }^{\circledR} 2300$ Analyzer Unit, Foss Analytical AB, Sweden) and the ash content was determined according to the AOAC (2000) method.

\section{pH values}

The $\mathrm{pH}$ values of the samples were measured using a $\mathrm{pH}$ meter (Model 340, Mettler-Toledo GmbH, Switzerland). The $\mathrm{pH}$ of the raw ground pork was measured after blending $5 \mathrm{~g}$ of sample with $20 \mathrm{~mL}$ of distilled water for $60 \mathrm{~s}$ in a homogenizer (Ultra-Turrax SK15, Janke \& Kunkel, Germany).

\section{Instrumental color}

The instrumental color analyses of the raw pork patties were conducted as follows. The color measurements were acquired using a colorimeter (Chroma meter CR-210, Minolta, Japan; illuminate $\mathrm{C}$, calibrated with a white standard plate CIE L ${ }^{*}=97.83, \mathrm{CIE} \mathrm{a}^{*}=-0.43, \mathrm{CIE} \mathrm{b}^{*}=$ +1.98 ), which consisted an $8 \mathrm{~mm}$ diameter measuring area and a $50 \mathrm{~mm}$ diameter illumination area. The color values (CIE L*, $a^{*}$, and $b^{*}$ ) were measured on the sample surfaces and data were collected in triplicate for each sample.

\section{Thiobarbituric acid reaction substance (TBARS) values}

Lipid oxidation was assessed in triplicate using the 2thiobarbituric acid (TBA) assay described by Tarladgis et al. (1960) with minor modifications. Fifty $\mathrm{mL}$ of distilled water was added to $10 \mathrm{~g}$ of sample prior to homogenizing with a homogenizer (AM-7, Nihonseiki Kaisha Ltd., Japan) at 10,000 rpm for $2 \mathrm{~min}$. The cup used for blending was washed with an additional $47.5 \mathrm{~mL}$ of distilled water, which was added to the same distillation flask containing $2.5 \mathrm{~mL}$ of $4 \mathrm{~N} \mathrm{HCl}$ and a few drops of an antifoam agent, silicone o/w (KMK-73, Shin-Etsu Silicone Co., Ltd., Korea). The mixture was distilled and $50 \mathrm{~mL}$ 
distillate was collected. Five mL of $0.02 \mathrm{M}$ TBA in $90 \%$ acetic acid (TBA reagent) was added to a vial containing $5 \mathrm{~mL}$ of the distillate and mixed well. The vials were capped and heated in a boiling water bath for $30 \mathrm{~min}$ to develop the chromogen and cooled to room temperature. The absorbance was measured at $538 \mathrm{~nm}$, against a blank prepared with distilled water $(5 \mathrm{~mL})$ and TBA-reagent $(5$ $\mathrm{mL}$ ), using a UV/VIS spectrophotometer (Libra S22, Biochrom Ltd., England). TBARS values were calculated by multiplying the absorbance by $73 \%$, which was the recovery of the standard from meat, resulting in a $\mathrm{K}$ value of 7.8 . The TBA values were calculated as mg malondialdehyde (MDA)/kg sample.

\section{TBARS (malonaldehyde $\mathrm{mg} /$ sample $\mathrm{kg}$ )}

$$
=\mathrm{OD} \text { value } \times 7.8
$$

\section{Conjugated dienes (CD) and free fatty acids (FFA)}

Lipid extraction was conducted according to the method described by Folch (Folch et al., 1957) using a chloroform:methanol solvent system (2:1). The lipid extracts were evaporated and concentrated in a rotary evaporator (Rotary evaporator N-1000, Eyela, Japan). The extracted lipids were placed then analyzed by $\mathrm{CD}$ and FFA. The CD concentrations were determined as described by Prasetyo et al. (2008). Fifteen mg of extracted lipid sample was placed into a $25 \mathrm{~mL}$ volumetric flask and massed up with isooctane. The samples were mixed and the absorbance was read at $234 \mathrm{~nm}$ against a blank of isooctane using a UV/VIS spectrophotometer (Libra S22, Biochrom Ltd., England). The CD concentration was calculated using a molar extinction coefficient of $25,200 / \mathrm{M} / \mathrm{cm}$ and expressed as $\mu \mathrm{mol} / \mathrm{mg}$ meat lipid sample.

The free fatty acids (FFA) values of the extracted lipids were determined by AOCS (1987), and calculated as fol- lows: FFA $(\%)=(\mathrm{S}-\mathrm{B}) \times \mathrm{M}_{0} \times \mathrm{N} \times \mathrm{F} / \mathrm{W}[\mathrm{S}=$ titration amount of sample; $\mathrm{B}=$ titration amount of blank; $\mathrm{M}_{0}=$ molecular weight of $\mathrm{KOH} ; \mathrm{F}=$ titer of $0.01 \mathrm{~N} \mathrm{KOH} ; \mathrm{N}=$ normality of $\mathrm{KOH} ; \mathrm{W}=$ sample weight $(\mathrm{g})]$.

\section{Statistical analysis}

Analysis of variance was performed on all the variables measured using the General Linear Model (GLM) procedure of the SAS statistical package (SAS Institute, Inc., 2010). Duncan's multiple range test $(p<0.05)$ was used to determine the differences between treatment means.

\section{Results and Discussion}

\section{Chemical compositions}

The chemical compositions of the ground pork with GLP and GSP are shown in Table 1. There were no significant differences in the fat, protein, and moisture contents of the samples presented no significant differences $(p>0.05)$. The ash contents of samples with GLP and GSP were higher than the control and AS. The ash contents of GSP2 was the highest in all treatments $(p<0.05)$, since GSP had a higher ash contents than GLP. Lee et al. (2005) reported similar results, where the addition of citron peel powder resulted in an increase in the ash contents of emulsion-type pork sausages. Also, Kim et al. (2011b) observed that ash contents of pork sausage increased with the addition of citrus peel and dried Lentinus edodes powders.

\section{pH values evaluations}

The $\mathrm{pH}$ values of the raw ground pork with GLP and GSP ranged from 5.61 to 5.85 (Table 2). The $\mathrm{pH}$ values of all samples decreased up to day 7 . This decrease in the $\mathrm{pH}$ value was caused by lactic acid, which is synthesized

Table 1. Chemical composition (\%) in raw ground pork treated with differernt levels of goldenrod leaf powder and goldenrod stem powder during $15 \mathrm{~d}$ of storage at $4^{\circ} \mathrm{C}$

\begin{tabular}{|c|c|c|c|c|}
\hline \multirow{2}{*}{ Treatment $^{1)}$} & \multicolumn{4}{|c|}{ Properties (\%) } \\
\hline & Fat & Protein & Moisture & Ash \\
\hline Control & $22.52 \pm 0.29$ & $16.08 \pm 0.61$ & $58.16 \pm 0.31$ & $2.17 \pm 0.18^{b}$ \\
\hline GLP1 & $22.44 \pm 0.24$ & $16.08 \pm 0.10$ & $58.17 \pm 0.28$ & $2.24 \pm 0.22^{\mathrm{ab}}$ \\
\hline GLP2 & $22.61 \pm 0.18$ & $16.05 \pm 0.17$ & $58.17 \pm 0.69$ & $2.42 \pm 0.17^{\mathrm{ab}}$ \\
\hline GSP1 & $22.64 \pm 0.40$ & $16.11 \pm 0.02$ & $58.12 \pm 0.34$ & $2.29 \pm 0.21^{\mathrm{ab}}$ \\
\hline GSP2 & $22.66 \pm 0.12$ & $16.03 \pm 0.05$ & $58.03 \pm 0.01$ & $2.56 \pm 0.04^{\mathrm{a}}$ \\
\hline AS & $22.64 \pm 0.05$ & $16.12 \pm 0.03$ & $58.05 \pm 0.09$ & $2.17 \pm 0.04^{\mathrm{a}}$ \\
\hline
\end{tabular}

All values are mean $\pm \mathrm{SD}$ of three replicates.

a, beans within a column with different letters are significantly different $(p<0.05)$.

${ }^{1)}$ Control, pork patties without antioxidant; GLP1, pork patties with $0.1 \%$ goldenrod leaf powder; GLP2, pork patties with $0.5 \%$ goldenrod leaf powder; GSP1, pork patties with $0.1 \%$ goldenrod stem powder; GSP2, pork patties with $0.5 \%$ goldenrod stem powder and AS, pork patties with $0.05 \%$ ascorbic acid 
Table 2. pH value in raw ground pork treated with different levels of goldenrod leaf powder and goldenrod stem powder during $15 \mathrm{~d}$ of storage at $4^{\circ} \mathrm{C}$

\begin{tabular}{lccccc}
\hline \hline \multirow{2}{*}{ Treatment $^{1)}$} & \multicolumn{5}{c}{ Storage day } \\
\cline { 2 - 6 } & 1 & 4 & 7 & 10 & 15 \\
\hline Control & $5.72 \pm 0.02^{\mathrm{Ac}}$ & $5.69 \pm 0.03^{\mathrm{ABb}}$ & $5.66 \pm 0.02^{\mathrm{Bbc}}$ & $5.69 \pm 0.03^{\mathrm{ABb}}$ & $5.71 \pm 0.01^{\mathrm{Acd}}$ \\
GLP1 & $5.78 \pm 0.01^{\mathrm{Ab}}$ & $5.71 \pm 0.09^{\mathrm{BCb}}$ & $5.68 \pm 0.03^{\mathrm{Cb}}$ & $5.75 \pm 0.01^{\mathrm{ABa}}$ & $5.76 \pm 0.01^{\mathrm{ABb}}$ \\
GLP2 & $5.85 \pm 0.01^{\mathrm{Aa}}$ & $5.83 \pm 0.03^{\mathrm{Aa}}$ & $5.74 \pm 0.05^{\mathrm{Ca}}$ & $5.78 \pm 0.05^{\mathrm{BCa}}$ & $5.81 \pm 0.01^{\mathrm{ABa}}$ \\
$\mathrm{GSP} 1$ & $5.71 \pm 0.01^{\mathrm{Ac}}$ & $5.70 \pm 0.02^{\mathrm{Ab}}$ & $5.65 \pm 0.01^{\mathrm{Bbc}}$ & $5.71 \pm 0.03^{\mathrm{Ab}}$ & $5.72 \pm 0.01^{\mathrm{Ac}}$ \\
GSP2 & $5.72 \pm 0.01^{\mathrm{Ac}}$ & $5.70 \pm 0.01^{\mathrm{Bb}}$ & $5.67 \pm 0.01^{\mathrm{Cb}}$ & $5.70 \pm 0.02^{\mathrm{ABb}}$ & $5.72 \pm 0.01^{\mathrm{Ac}}$ \\
$\mathrm{AS}$ & $5.71 \pm 0.02^{\mathrm{Ac}}$ & $5.69 \pm 0.01^{\mathrm{Ab}}$ & $5.61 \pm 0.05^{\mathrm{Bc}}$ & $5.69 \pm 0.02^{\mathrm{Ab}}$ & $5.70 \pm 0.01^{\mathrm{Ad}}$ \\
\hline
\end{tabular}

All values are mean $\pm \mathrm{SD}$ of three replicates.

${ }^{A-C}$ Means within a row with different letters are significantly different $(p<0.05)$.

${ }^{\mathrm{a}-\mathrm{d}}$ Means within a column with different letters are significantly different $(p<0.05)$.

${ }^{1)}$ Control, pork patties without antioxidant; GLP1, pork patties with $0.1 \%$ goldenrod leaf powder; GLP2, pork patties with $0.5 \%$ goldenrod leaf powder; GSP1, pork patties with $0.1 \%$ goldenrod stem powder; GSP2, pork patties with $0.5 \%$ goldenrod stem powder and AS, pork patties with $0.05 \%$ ascorbic acid

by lactobacilli and dissociated $\mathrm{CO}_{2}$ from muscle tissue (Panerasand Bloukas, 1988). GLP2 had the highest $\mathrm{pH}$ value at all the storage times $(p<0.05)$. Choe et al. (2011) found that the addition of goldenrod leaf powder increased the $\mathrm{pH}$ values of emulsion-type sausages, due to the high $\mathrm{pH}$ value of goldenrod powder. However, the addition of GSP did not result in a significant change in the $\mathrm{pH}$ value $(p>0.05)$. After $7 \mathrm{~d}, \mathrm{pH}$ values increased in all treatment. Byun et al. (2001) reported similar results, where the $\mathrm{pH}$ values of ground pork containing a garlic extracts decreased until day 4 and then increased.

\section{Instrumental color evaluation}

Meat color is an important factor to consumers and a decrease of the redness color is considered unacceptable by consumers (Renerre, 2000). Meat discoloration is caused by lipid oxidation, which promotes myoglobin oxidation in meat and meat product (Yin and Faustman, 1993). Table 3 shows that the addition of GLP and GSP had an effect on the color values (CIE $L^{*}, a^{*}$ and $b^{*}$ ) of raw ground pork during storage times of $15 \mathrm{~d}$. CIE $\mathrm{L}^{*}$ values of all samples increased with an increase in the storage time for all treatment. Treatments with GLP and GSP presented lower CIE $\mathrm{L}^{*}$ values than the control, which occurred because of low CIE L* values of GLP and GSP. Choe et al (2011) reported that the CIE L* values of GLP and GSP were 33.16 and 61.30, respectively. Samples containing GLP and GSP had a lower CIE $\mathrm{a}^{*}$ value and higher $\mathrm{CIE}^{*}{ }^{*}$ value. Especially GLP2 presented the lowest $a^{*}$ value and the highest $b^{*}$ value. These change in the CIE $a^{*}$ value and CIE $b^{*}$ value was caused by the deep green color of GSP and GLP. Choe et al. (2011) observed a similar result that pork sausage containing GLP and
GSP presented low CIE $a^{*}$ value and the high CIE $b^{*}$ value as increased addition of GLP and GSP. However, the addition of GSP and GLP decreased drop of CIE a ${ }^{*}$ value. The CIE a ${ }^{*}$ values of the control, GLP2, and GSP2 samples decrease by $5.45,0.17$, and 3.65 , respectively after $15 \mathrm{~d}$ of chilled storage. The decrease in the CIE $\mathrm{a}^{*}$ value is related to metmyoglobin which is generated by the oxidation of myoglobin (Nerín et al., 2006). Also, Bekhit et al. (2003) observed that natural antioxidants reduced the production of metmyoglobin in beef patties. These results mean that the antioxidant activity of GLP and GSP may improve the color stability of raw ground pork. The findings are in agreement with results presented by Jo et al. (2003), who reported that the addition of green tea extract powder decreased the CIE a* value of raw pork patties and prevented color deterioration.

\section{Conjugated diens (CD) and free fatty acids (FFA)}

Unsaturated fatty acids are readily exposed to oxidation and oxidized fatty acids create conjugated dienes, which contains two carbon-carbon double bonds separated by one carbon-carbon single bond. Pork contains an abundant amount of polyunsaturated fatty acids (Hallenstvedt et al., 2012). These fatty acids can produce conjugated dienes, which can be measured spectrophotomerically during the early lipid oxidation stage (Teets and Were, 2008). The change in CD values due to the addition of GLP and GSP is presented in Fig. 1. The CD values of the control significantly increased up to day 7 , and then significantly decreased up to day $15(p<0.05)$. Samples containing GLP and GSP and AC had higher CD values up to day 10 , and then significantly decreased $(p<0.05)$. This trend was caused by transformation of conjugated diene 
Table 3. Color evaluation in raw ground pork added different levels of goldenrod leaf powder and goldenrod stem powder during $10 \mathrm{~d}$ of storage at $4^{\circ} \mathrm{C}$

\begin{tabular}{|c|c|c|c|c|c|c|}
\hline \multirow{2}{*}{\multicolumn{2}{|c|}{ Treatment $^{1)}$}} & \multicolumn{5}{|c|}{ Storage day } \\
\hline & & 1 & 4 & 7 & 10 & 15 \\
\hline \multirow{6}{*}{ CIE L* } & Control & $73.60 \pm 1.41^{\mathrm{Cc}}$ & $73.56 \pm 1.30^{\mathrm{BCc}}$ & $73.47 \pm 0.96^{\mathrm{Cc}}$ & $74.34 \pm 1.95^{\mathrm{ABbc}}$ & $75.85 \pm 0.59^{\mathrm{Abc}}$ \\
\hline & GLP1 & $70.07 \pm 0.97^{\mathrm{ABb}}$ & $69.68 \pm 1.19^{\mathrm{Bbc}}$ & $70.48 \pm 1.24^{\mathrm{ABb}}$ & $70.96 \pm 0.57^{\mathrm{ABb}}$ & $71.30 \pm 1.18^{\mathrm{Ab}}$ \\
\hline & GLP2 & $62.42 \pm 1.69^{\mathrm{Be}}$ & $61.78 \pm 1.65^{\mathrm{Bd}}$ & $63.43 \pm 0.94^{\mathrm{ABd}}$ & $63.52 \pm 1.42^{\mathrm{ABd}}$ & $64.78 \pm 0.92^{\mathrm{Ad}}$ \\
\hline & GSP1 & $72.30 \pm 1.29^{\mathrm{Ba}}$ & $72.77 \pm 1.08^{\mathrm{ABa}}$ & $73.35 \pm 1.35^{\mathrm{ABa}}$ & $73.01 \pm 0.86^{\mathrm{ABa}}$ & $74.09 \pm 0.90^{\mathrm{Aa}}$ \\
\hline & GSP2 & $69.56 \pm 0.73^{\mathrm{Bb}}$ & $70.94 \pm 0.93^{\mathrm{Ab}}$ & $70.21 \pm 1.01^{\mathrm{ABb}}$ & $70.98 \pm 1.38^{\mathrm{Ab}}$ & $71.14 \pm 0.71^{\mathrm{Abc}}$ \\
\hline & AS & $66.10 \pm 1.35^{\mathrm{Bd}}$ & $69.04 \pm 0.97^{\mathrm{Ac}}$ & $68.29 \pm 2.05^{\mathrm{Ac}}$ & $69.28 \pm 1.15^{\mathrm{Ac}}$ & $70.04 \pm 1.00^{\mathrm{Ac}}$ \\
\hline \multirow{6}{*}{ CIE $a^{*}$} & Control & $9.40 \pm 0.45^{\mathrm{Ab}}$ & $6.78 \pm 0.13^{\mathrm{Bb}}$ & $6.44 \pm 0.24^{\mathrm{Cb}}$ & $6.18 \pm 0.14^{\mathrm{Db}}$ & $3.95 \pm 0.49^{\mathrm{Ec}}$ \\
\hline & GLP1 & $7.64 \pm 0.35^{\mathrm{Ac}}$ & $4.83 \pm 0.22^{\mathrm{Bc}}$ & $3.67 \pm 0.41^{\mathrm{Cd}}$ & $3.69 \pm 0.43^{\mathrm{Cc}}$ & $3.56 \pm 0.52^{\mathrm{Cc}}$ \\
\hline & GLP2 & $0.05 \pm 0.72^{\mathrm{Ae}}$ & $-1.19 \pm 1.26^{\mathrm{Bd}}$ & $-0.59 \pm 1.06^{\mathrm{ABe}}$ & $0.17 \pm 0.33^{\mathrm{Ad}}$ & $-0.12 \pm 0.58^{\mathrm{Ad}}$ \\
\hline & GSP1 & $8.87 \pm 0.40^{\mathrm{Ab}}$ & $5.49 \pm 0.50^{\mathrm{Cc}}$ & $5.65 \pm 0.56^{\mathrm{Cc}}$ & $7.20 \pm 0.93^{\mathrm{Bb}}$ & $5.48 \pm 0.50^{\mathrm{Cb}}$ \\
\hline & GSP2 & $6.85 \pm 0.51^{\mathrm{Ad}}$ & $5.43 \pm 0.32^{\mathrm{Bc}}$ & $3.28 \pm 0.54^{\mathrm{Dd}}$ & $3.80 \pm 0.23^{\mathrm{Cc}}$ & $3.20 \pm 0.37^{\mathrm{Dc}}$ \\
\hline & AS & $12.57 \pm 0.52^{\mathrm{Aa}}$ & $8.94 \pm 0.38^{\mathrm{Ba}}$ & $8.49 \pm 0.53^{\mathrm{Ca}}$ & $8.43 \pm 0.39^{\mathrm{Ca}}$ & $8.38 \pm 0.36^{\mathrm{Da}}$ \\
\hline \multirow{6}{*}{ CIE b* } & Control & $13.42 \pm 0.56^{\mathrm{c}}$ & $13.80 \pm 0.53^{d}$ & $13.60 \pm 1.13^{\mathrm{d}}$ & $12.83 \pm 0.75^{\mathrm{d}}$ & $13.55 \pm 0.63^{d}$ \\
\hline & GLP1 & $14.77 \pm 0.31^{\mathrm{b}}$ & $14.92 \pm 0.97^{\mathrm{c}}$ & $14.27 \pm 0.40^{\mathrm{cd}}$ & $14.73 \pm 0.39^{c}$ & $14.43 \pm 0.57^{\mathrm{c}}$ \\
\hline & GLP2 & $16.88 \pm 1.33^{\mathrm{a}}$ & $17.75 \pm 1.15^{\mathrm{a}}$ & $17.00 \pm 0.54^{\mathrm{a}}$ & $17.30 \pm 0.77^{\mathrm{a}}$ & $17.25 \pm 0.64^{\mathrm{a}}$ \\
\hline & GSP1 & $14.62 \pm 0.52^{b}$ & $14.71 \pm 0.69^{\mathrm{cd}}$ & $14.49 \pm 0.47^{\mathrm{c}}$ & $14.99 \pm 0.42^{\mathrm{bc}}$ & $15.01 \pm 0.56^{\mathrm{c}}$ \\
\hline & GSP2 & $16.44 \pm 0.67^{\mathrm{Aa}}$ & $15.93 \pm 0.49^{\mathrm{ABb}}$ & $16.19 \pm 0.72^{\mathrm{ABb}}$ & $15.54 \pm 0.41^{\mathrm{Bb}}$ & $16.15 \pm 0.61^{\mathrm{ABb}}$ \\
\hline & $\mathrm{AS}$ & $14.34 \pm 1.21^{\mathrm{Bc}}$ & $13.99 \pm 0.40^{\mathrm{Ccd}}$ & $14.14 \pm 0.56^{\mathrm{BCcd}}$ & $15.39 \pm 0.55^{\mathrm{Abc}}$ & $15.11 \pm 1.06^{\mathrm{ABc}}$ \\
\hline
\end{tabular}

All values are mean \pm SD of three replicates.

A-E Means within a row with different letters are significantly different $(p<0.05)$.

${ }^{\mathrm{a}-\mathrm{e}}$ Means within a column with different letters are significantly different $(p<0.05)$.

${ }^{1)}$ Control, pork patties without antioxidant; GLP1, pork patties with $0.1 \%$ goldenrod leaf powder; GLP2, pork patties with 0.5\% goldenrod leaf powder; GSP1, pork patties with $0.1 \%$ goldenrod stem powder; GSP2, pork patties with $0.5 \%$ goldenrod stem powder and AS, pork patties with $0.05 \%$ ascorbic acid

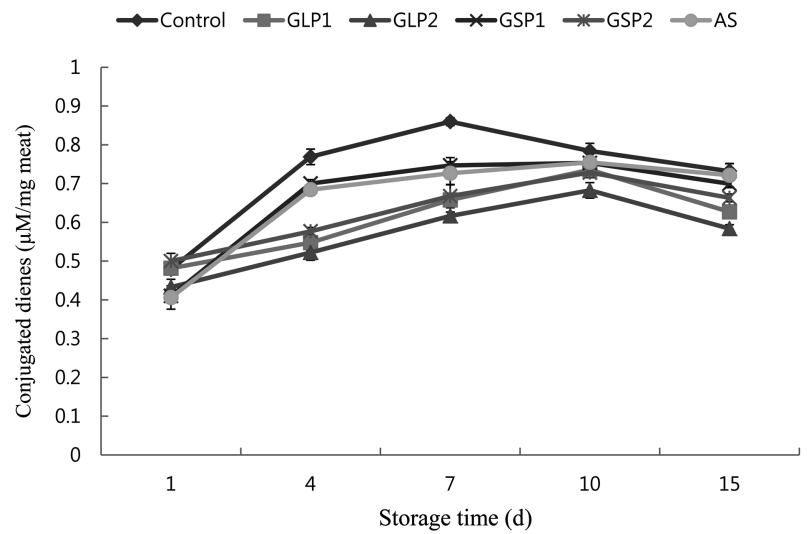

Fig. 1. Change in conjugated dienes $(\mu \mathrm{M} / \mathrm{mg}$ meat) of ground pork meat added goldenrod leaf powder (GLP) and goldenrod stem powder (GSP) on during storage days. All values are mean $\pm \mathrm{SD}$ of three replicates.

hydroperoxides to secondary products after $\mathrm{CD}$ formation peaked (Juntachote et al., 2007b). Frankel (1996) reported that the formation of conjugated dienes was related to the production of hydroperoxides, which are formed during initial stages of lipid oxidation. The CD values then decreased because conjugated diene hydroperoxides might have decomposed to secondary products. These results are agreement with the finding of Juntachote et al. (2007a), who reported a decrease in the $\mathrm{CD}$ values of cooked ground pork containing holy basin after $7 \mathrm{~d}$ of chilled storage. The addition of GLP and GSP decreased the CD values and delayed the peak of the $C D$ value during $15 \mathrm{~d}$ of storage. Especially, GLP2 had a lower the CD peak values than control $(p<0.05)$. A previous study reported that phenolic acid and isoflavonoids possess antioxidant activity and can lower the CD values (Seo and Morr, 1984).

Tri-glycerides and phospholipids were decomposed to free fatty acids by lipid oxidation during the $15 \mathrm{~d}$ of storage; thus, free fatty acid (FFA) analysis (Dempster et al., 1985) was used as an indicator of oxidation stability. Table 4 shows that the addition of GLP and GSP affected the FFA values of raw ground pork during chilled storage. The FFA values ranged from 0.085 to $1.656 \%$. For all treatments, FFA value increased with an increase in storage times $(p<0.05)$. Lefebvre et al. (1994) observed that the FFA value increased in irradiated ground beef during storage time. Sample containing GLP and GSP 
Table 4. Free fatty acid (\%) values in raw ground pork added different levels of goldenrod leaf powder and goldenrod stem powder during $15 \mathrm{~d}$ of storage at $4^{\circ}$

\begin{tabular}{lccccc}
\hline \hline \multirow{2}{*}{ Treatment $^{1)}$} & \multicolumn{5}{c}{ Storage day } \\
\cline { 2 - 6 } & 1 & 4 & 7 & 10 & 15 \\
\hline Control & $0.653 \pm 0.19^{\mathrm{Da}}$ & $0.775 \pm 0.20^{\mathrm{Ca}}$ & $0.838 \pm 0.19^{\mathrm{Ca}}$ & $1.105 \pm 0.19^{\mathrm{Ba}}$ & $1.656 \pm 0.35^{\mathrm{Aa}}$ \\
GLP1 & $0.212 \pm 0.07^{\mathrm{Ec}}$ & $0.295 \pm 0.06^{\mathrm{Dcd}}$ & $0.438 \pm 0.17^{\mathrm{Cd}}$ & $0.664 \pm 0.13^{\mathrm{Bd}}$ & $0.809 \pm 0.19^{\mathrm{Ac}}$ \\
GLP2 & $0.168 \pm 0.08^{\mathrm{Dc}}$ & $0.210 \pm 0.06^{\mathrm{De}}$ & $0.379 \pm 0.18^{\mathrm{Ce}}$ & $0.563 \pm 0.14^{\mathrm{Be}}$ & $0.622 \pm 0.22^{\mathrm{Ad}}$ \\
GSP1 & $0.171 \pm 0.10^{\mathrm{Dc}}$ & $0.323 \pm 0.05^{\mathrm{Cbc}}$ & $0.751 \pm 0.13^{\mathrm{Bb}}$ & $0.805 \pm 0.12^{\mathrm{Ac}}$ & $0.832 \pm 0.19^{\mathrm{Ac}}$ \\
GSP2 & $0.085 \pm 0.13^{\mathrm{Ed}}$ & $0.253 \pm 0.06^{\mathrm{Dde}}$ & $0.520 \pm 0.15^{\mathrm{Cc}}$ & $0.633 \pm 0.15^{\mathrm{Bd}}$ & $0.809 \pm 0.21^{\mathrm{Ac}}$ \\
AS & $0.298 \pm 0.02^{\mathrm{Eb}}$ & $0.352 \pm 0.02^{\mathrm{Db}}$ & $0.786 \pm 0.01^{\mathrm{Cab}}$ & $0.890 \pm 0.01^{\mathrm{Bb}}$ & $1.179 \pm 0.02^{\mathrm{Ab}}$ \\
\hline
\end{tabular}

All values are mean $\pm \mathrm{SD}$ of three replicates.

${ }^{\mathrm{A}-\mathrm{E}}$ Means within a row with different letters are significantly different $(p<0.05)$.

${ }^{\mathrm{a}-\mathrm{e}}$ Means within a column with different letters are significantly different $(p<0.05)$.

${ }^{1)}$ Control, pork patties without antioxidant; GLP1, pork patties with $0.1 \%$ goldenrod leaf powder; GLP2, pork patties with $0.5 \%$ goldenrod leaf powder; GSP1, pork patties with $0.1 \%$ goldenrod stem powder; GSP2, pork patties with $0.5 \%$ goldenrod stem powder and AS, pork patties with $0.05 \%$ ascorbic acid

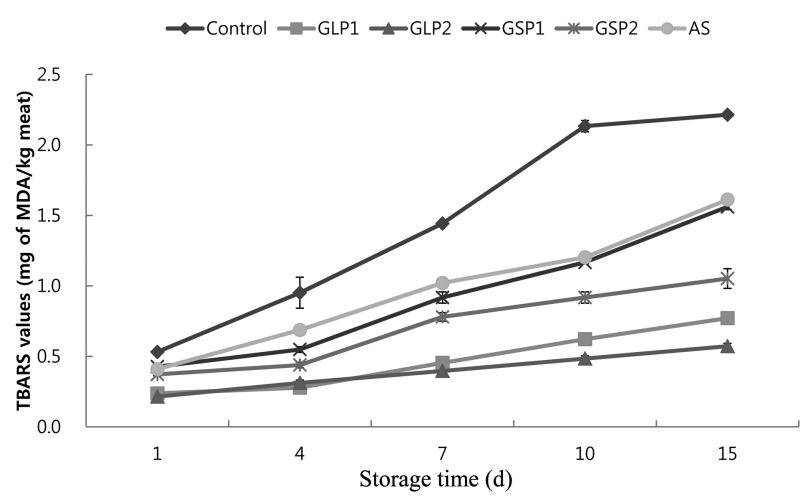

Fig. 2. Change in thiobarbituric acid reaction substance (TBARS) values (mg of MDA/kg meat) of ground pork meat added goldenrod leaf powder (GLP) and goldenrod stem powder(GSP) during storage days. All values are mean $\pm \mathrm{SD}$ of three replicates.

had a lower FFA value than the control and AS over the storage period. Especially, GLP2 had significantly lower FFA value than the other treatment throughout storage except for day $1(p<0.05)$.

\section{Thiobarbituric acid reaction substances (TBARS) values}

TBARS values of raw ground pork with GLP and GSP during chilled storage are presented in Fig. 2. The TBARS value measure the concentration of malondialdehyde, which is a secondary lipid oxidation product of meat products. The TBARS values of the samples increased significantly an increase in the storage time $(p<0.05)$. Samples with GLP had lower TBARS values and delayed lipid oxidation $(p<0.05)$. Especially, GLP2 had the lowest TBARS value during throughout storage. Sample with GSP also had lower TBARS values than the control and sample with AS. On day 15, the control had the highest TBARS value, which was followed by AS, GSP1, GSP2, GLP1, and GLP2. These decreases in TBARS value indicates that GLP and GSP prevented lipid oxidation in the ground pork samples and acted as an antioxidant during storage. Many previous studies have reported that the addition of antioxidant decrease the TBARS value by inhibiting of lipid oxidation. Chang et al. (2011) observed that the addition of chitosan-glucose maillard reaction product to pork meat lowered the TBARS value when compared to control samples during refrigerated storage. The antioxidant activity of the goldenrod leaf and stem powder may have originated from phenolic compounds and vitamins present in the goldenrod. Rodríguez-Carpena et al. (2011) reported that the addition of phenolic-rich avocado extracts inhibited lipid oxidation of raw porcine patties. Li et al. (2006) also found that the large amount of phenolics contained in rind powder extracts presented strong antioxidant activity. Juntachote et al. (2007b) studied the effect of galangal powder and its ethanolic extracts on oxidation stability. The antioxidant activity of galangal powder and extracts may be related to their phenolic compounds, which can quench reactive oxygen species. In previous studies, natural extracts that contained phenolic compounds were shown to inhibited the generation of free radical and free radical chain reactions (Shan et al., 2009; Ibrahim et al., 2010).

\section{Acknowledgements}

This study was supported by the Ministry of Agriculture and Forestry (610002-03-2-SB120), Republic of Korea. The authors also partially supported by the Brain 
Korean 21 (BK 21) Project from Ministry of Education and Human Resources Development.

\section{References}

1. AOAC (2000) Official methods of analysis. 16th ed, Association of Official Analytical Chemists, Washington, DC.

2. AOCS (1987) Official and tentative methods of the American Oil Chemist's Society. 3rd ed, Champaign, Il, USA.

3. Bandyopadhyay, M., Chakraborty, R., and Raychaudhuri, U. (2008) Antioxidant activity of natural plant sources in dairy dessert (Sandesh) under thermal treatment. Food Sci. Technol. Int. 41, 816-825.

4. Bekhit, A. E. D., Geesinkb, G. H., Iliana, M. A., Mortona, J. D., and Bickerstaffea, R. (2003) The effects of natural antioxidants on oxidative processes and etmyoglobin reducing activity in beef patties. Food Chem. 81, 175-187.

5. Byun, P. H., Jung, J. H., Kim, W. J., and Yoon, S. K. (2001) Effects of garlic addition on lipid oxidation of ground pork during storage. Korean J. Soc. Food Cookery Sci. 17, 117122.

6. Chang, H. L., Chen, Y. C., and Tan, F. J. (2011) Antioxidative properties of a chitosan-glucose Maillard reaction product and its effect on pork qualities during refrigerated storage. Food Chem. 124, 589-595.

7. Chen, C. H., Pearson, A. M., and Gray, J. I. (1992) Effects of synthetic antioxidants (BHA, BHT and PG) on the mutagenicity of IQ-like compounds. Food Chem. 43, 177-183.

8. Choe, J. H., Kim, H. Y., Han, D. J., Kim, Y. J. Park, J. H., Ham, Y. K., and Kim, C. J. (2011) Effect of goldenrod (Solidago virgaurea) leaf and stem powder on physical and sensory characteristics of emulsion-type sausages. Korean $J$. Food Sci. An. 31, 668-675.

9. Choi, I. Y., Song, Y. J., and Lee, W. H. (2010) DPPH radical scavenging effect and antimicrobial activities of some herbal extracts. Kor. J. Hort. Sci. Technol. 28, 871-876.

10. Dempster, J. F., Hawrysh, Z. J., Shand, P., Lahola-Chomiak, L., and Corletto, L. (1985) Effect of low dose irradiation (radurisation) on the shelf life of beef burgers stored at $3{ }^{\circ} \mathrm{C}$. Food Tech. 20, 145-154.

11. Folch, J., Lee, M., and Stanley, S. G. H. (1957) A simple method for the isolation and purification of total lipids from animal tissues. J. Biol. Chem. 226, 497-509.

12. Frankel, E. N. (1950) Lipid oxidation Pray. Lipid Res. Oxford, United kondom, Vol. 19, pp. 1-22.

13. Hallenstvedt, E., Øverland, M., Rehnberg, A., Kjos, N. P., and Thomassen, M. (2012) Sensory quality of short- and longterm frozen stored pork products. Influence of diets varying in polyunsaturated fatty acid (PUFA) content and iodine value. Meat Sci. 90, 244-251.

14. Ibrahim, H. M., Abou-Arab, A. A., and Abu, S. F. M. (2010) Addition of some natural plant extracts and their effects on Lamb patties quality. J Food Technol. 8, 134-142.

15. Jo, C., Son, J. H., Son, C. B., and Byun, M. W. (2003) Functional properties of raw and cooked pork patties with added irradiated, freeze-dried green tea leaf extract powder during storage at $4{ }^{\circ} \mathrm{C}$. Meat Sci. 64, 13-17.

16. Jutachote, T. Berghofer, E., Siebenhandl, S., Bauer, F. (2007a) Antioxidative effect of added dried Holy basil and its ethanolic extracts on susceptibility of cooked ground pork to lipid oxidation. Food Chem. 100, 12-135.

17. Jutachote, T., Berghofer, E., Siebenhandl, S., and Bauer, F. (2007b) The effect of dried galangal powder and its ethanolic extracts on oxidative stability in cooked ground pork. $L W T$ Food Sci. Technol. 40, 324-330.

18. Lee, J. R., Jung, J. D., Hah, Y. J., Lee, J. W., Lee, J. D., Park, G. B., and Kwack, S. J. (2005) Effects of addition of citron peel powder on the proximate composition, minerals, vitamin A, C content and fatty acid composition of emulsiontype sausage. J. Anim. Sci. Technol. 47, 99-106.

19. Lefebvre, N., Thibault, C., Charbonneau, R., and Piette, J. P. G. (1994) Improvement of shelf-life and wholesomeness of ground beef by irradiation, 2. Chemical analysis and sensory evaluation. Meat Sci. 36, 371-380.

20. Li, Y., Guo, C., Yang, J., Wei, J., Xu, J., and Cheng, S. (2006) Evaluation of antioxidant properties of pomegranate peel extract in comparison with pomegranate pulp extract. Food Chem. 96, 254-260.

21. Linda J. M. (2005) Bailey's Industrial oil and fat products edible oil and fat products: chemistry, properties, and health effects. 6th ed, John Wiley \& Sons, Inc., Hoboken, New Jersey, Vol.1, pp. 413-430.

22. Kim, D. H., An, B. J., Kim, S. G., Park, T. S., Park, G. H., and Son, J. H. (2011a) Anti-Inflammatory effect of Ligularia fischeri, Solidago virga-aurea and Aruncus dioicus complex extracts in raw 264.7 Cells. J. Life Sci. 21, 678-683.

23. Kim, J. H., Choi, J. R., and Kim, M. Y. (2011b) Sensory characteristics of pork sausages with added citrus peel and dried Lentinus edodes powders. J. Korean Soc. Food Sci Nutr. 40, 1623-1630.

24. McCarthy, T. L., Kerry, J. P., Kerry, J. F., Lynch, P. B., and Buckley, D. J. (2001) Evaluation of the antioxidant potential of natural food/plant extracts as compared with synthetic antioxidants and vitamin $\mathrm{E}$ in raw and cooked pork patties. Meat Sci. 57, 45-52.

25. Namiki, M. (1990) Antioxidants/antimutagens in food. Crit. Rev. Food Sci. 29, 273-300.

26. Nerín, C., Tovar, L., Djenane, D., Camo, J., Salafranca, J., Beltran, J. A. et al. (2006) Stabilization of beef meat by a new active packaging containing natural antioxidants. $J$. Agri. Food Chem. 54, 7840-7846.

27. Pannersas, E. D. and Bloukas, J. G. (1988) A study of quality characteristics of frankfurters during processing and storage. Proceed. 2nd Hellenic Cong. in Food Sci. Technol., Athens, Greece, pp. 411-417.

28. Prasetyo, M., Chia, M., Hughey, C., and Were, L. M. (2008) Utilization of electron beam irradiated almond skin powder as a natural antioxidant in ground top round beef. J. Food Sci. 73, 1-6.

29. Renerre, M. (2000) Review: Biochemical basis of fresh meat color. Proceedings of the 45th Int. Cong. Meat Sci. Technol., 
Yokohama, Japan, pp. 344-352.

30. Rodríguez-Carpena, J. G., Morcuende, D., and Estévez, M. (2011) Avocado by-products as inhibitors of color deterioration and lipid and protein oxidation in raw porcine patties subjected to chilled storage. Meat Sci. 89, 166-173.

31. SAS (2010) SAS/STAT Software for PC. Release 9.2, SAS Institute Inc., Cary, NC, USA.

32. Seo, A. and Morr, C. V. (1984) Improved high-performance liquid chromatographic analysis of phenolic acids and isoflavonoids from soybean protein products. J. Agr. Food Chem. 32, 530-533.

33. Shahidi, F. and Wanasundara, P. K. (1992) Phenolic antioxidants. Crit. Rev. Food Sci. 32, 67-103.

34. Shan, B., Cai, Y. Z., Brooks, J. D., and Corke, H. (2009) Antibacterial and antioxidant effects of five spice and herb extracts as natural preservatives of raw pork. J. Sci. Food Agr. 89, 1879-1885.

35. Sherwin, E. R. (1990) Antioxidants. In: Food Additives Branen, R. (ed), Dekker, NY, pp. 139.

36. Starks, C. M., Williams, R. B., Goering, M. G., O'NeilJohnson, M., Norman, V. L., Hu, J. F., Garo, E., Hough, G.
W., Rice, S. M., and Gary R. (2010) Eldridge antibacterial clerodane diterpenes from goldenrod (Solidago virgaurea). Phytochemistry 71, 104-109.

37. Sun, B. X. and Fukuhara, M. (1997) Effects of co-administration of butylated hydroxytoluene, butylated hydroxyanisole and flavonoids on the activation of mutagens and drugmetabolizing enzymes in mice. Toxicology 122, 61-72.

38. Tarladgis, B. G., Watts, B. M., and Younathan, M. T. (1960) A distillation method for the quantitative determination of malondialdehyde in rancid foods. J. Amer. Oil Chem. Soc. 37, 44-48.

39. Teets, A. S. and Were, L. M. (2008) Inhibition of lipid oxidation in refrigerated and frozen salted raw minced chicken breasts with electron beam irradiated almond skin powder. Meat Sci. 80, 1326-1332.

40. Yin, M. C. and Faustman, C. (1993) The influence of temperature, $\mathrm{pH}$, and phospholipid composition upon the stability of myoglobin and phospholipid: a liposome model. J. Agr. Food Chem. 41, 853-857.

(Received 2012.3.27/Revised 2012.11.7/Accepted 2012.11.28) 